\title{
Behaviors and Attitudes toward the Use of Complementary and Alternative Medicine among Korean Cancer Patients
}

\author{
Jung Hye Kwon, MD, $\mathrm{PhD}$ \\ Sang-Cheol Lee, MD, $P \mathrm{PD}^{2}$ \\ Myung Ah Lee, MD, PhD 3 \\ Yu Jung Kim, MD, $P h D^{4}$ \\ Jung Hun Kang, MD, PhD ${ }^{5}$ \\ Jin Young Kim, MD, $P h D^{6}$ \\ Hyo Jin Lee, MD, PhD ${ }^{7}$ \\ Woo Kyun Bae, MD, PhD \\ Mi-Jung Kim, MD ${ }^{9}$ \\ Eui Kyu Chie, MD, PhD'0 \\ Jin Kim, MD, PhD ${ }^{11}$ \\ Yeul Hong Kim, MD, PhD'2 \\ Hyun Cheol Chung, MD, PhD ${ }^{13}$ \\ Sun Young Rha, MD, PhD ${ }^{13}$
}

*A list author's affiliations appears at the end of the paper.

\section{Purpose}

A cross-sectional survey was conducted to explore the current awareness and use of complementary and alternative medicine (CAM), as well as attitudes toward CAM, in patients with cancer and their family members in South Korea.

\section{Materials and Methods}

Between September 21 and October 31, 2017, a 25-item questionnaire regarding CAM experiences among cancer patients and their family members was conducted in 10 oncology clinics in South Korea after institutional review board approval at each institution.

\section{Results}

In total, 283/310 patients were analyzed. The median age was 60 years, and $60 \%$ were male. Most of the patients were actively receiving anticancer treatment at the time of the survey. A total of 106 patients (37\%) had experienced a median of two types (interquartile range, 1 to 3) of CAM. Belief in CAM (odds ratio [OR], 3.015; 95\% confidence interval [CI], 1.611 to 5.640$)$ and duration of disease (OR, 1.012; $95 \% \mathrm{Cl}, 1.004$ to 1.020 ) were independent factors for using CAM in multivariable analysis. Belief in CAM was significantly associated with current use of CAM (OR, 3.633; 95\% Cl, 1.567 to 8.424). Lay referral was the most common reason for deciding to use CAM, and only $25 \%$ of patients (72/283) discussed CAM with their physicians.

\section{Conclusion}

Patient attitudes toward and confidence in CAM modalities were strongly associated with their CAM experiences, and only a small number of patients had an open discussion about CAM with their physicians. A patient education program for CAM is needed.

\section{Key words}

Complementary and alternative medicine, Neoplasms, Attitudes

Received March 11, 2019

Accepted June 7, 2019

Published Online June 7, 2019

*Jung Hye Kwon and Sang-Cheol Lee

contributed equally to this work.

\section{Introduction}

Cancer is a leading cause of death worldwide, including in South Korea. An estimated 14.1 million new cancer cases and 8.2 million cancer deaths occurred worldwide in 2012 [1], and a total of 214,701 cancer cases and 76,855 cancer deaths were reported in South Korea in 2015 [2]. Although significant medical advancements have led to improvements in overall survival, cancer remains a source of fear for patients and family members and is considered by most to be an incurable and life-threatening disease.

Many cancer patients have expressed interest in complementary and alternative medicine (CAM). Cancer survivors have been found to use CAM more than cancer-free populations [3]. The use of CAM was also found to be increased 
after cancer diagnosis, from $15.6 \%$ to $51.8 \%$ [4]. Large numbers of patients have reported using CAM during anticancer treatment-48.9\% in Italy [5], 37\% in Korea [6], and 29\% in the United Kingdom [7]. Cancer patients use CAM in various situations, from phase I clinical trials [8] to end-of-life care [6]; CAM use has also been reported in survivors [9].

Cancer patients use CAM for various reasons, including to alleviate cancer symptoms, enhance immunity, reduce the side effects of conventional medicine, and even as an alternative to conventional medicine [10]. WHO has defined $\mathrm{CAM}$ as "a broad set of health care practices that are not part of that country's own tradition or conventional medicine and are not fully integrated into the dominant health care system" [11]. The National Center for Complementary and Alternative Medicine (NCCAM) categorized CAM into five major classes: the whole medical system, mind-body medicine, biologically based practices, manipulative and bodybased practices, and energy medicine [12].

Most CAM modalities have no proven scientific data for to support their efficacy or safety, and drug interactions with conventional medicine can occur; thus, CAM could cause patients to be exposed to unexpectedly harmful situations [13]. In addition to the harmful side effects of or drug interactions with CAM, it can negatively impact patient prognosis by delaying the diagnosis and treatment of cancer [14] and can have an enormous impact on out-of-pocket costs [15].

This study was conducted to explore the characteristics of the use of CAM among cancer patients as well as factors related to their decision to disclose their use of CAM to their oncologists.

\section{Materials and Methods}

\section{Patients in the survey}

This cross-sectional study included both family members and cancer patients who received treatment between September 21 and October 31, 2017, at 10 oncology clinics in South Korea.

\section{Data collection}

The survey instrument was a 25-item questionnaire, consisting of demographics ( 2 items: age, sex), oncology-related variables ( 6 items: diagnosis, date of diagnosis, stage of cancer at the time of diagnosis, current stage of cancer, previous and current treatment), attitudes toward CAM (3 items: belief, self-confidence, unmet need in knowledge), various aspects of CAM experiences (9 items: types, experiences, sources, reasons, effectiveness, satisfaction, side effects, duration of usage, cost of CAM), and CAM consultation experience with a doctor (5 items). CAM types were categorized as follows for practical reasons, and each category has detailed examples frequently used in South Korea: Chinese medicine, health supplement, herb/folk remedy/dietary supplementation, imaginary therapy, and cell therapy, among others. Four medical oncologists, one radiational oncologist, and one oncology surgeon developed the questionnaire based on a literature review. Review, feedback, and revision of the questionnaire were conducted during investigator meetings. A paper self-report questionnaire was used for this survey with the support of clinical research coordinators to ensure proper data collection. Patients received a gift worth $\$ 5$ on the day of survey participation.

\section{Statistical analysis}

Descriptive statistics, including the means, medians, percentages, quartiles, and standard deviations, were used to summarize the demographics and the survey responses. Student's $t$ test and the Mann-Whitney $U$ test were used to determine the differences between the groups. A p-value of $<0.05$ was considered statistically significant. IBM SPSS statistics ver. 24 (IBM Corp., Armonk, NY) was used for all statistical analyses. Graphs were produced using Excel software based on SPSS output data.

\section{Ethical statement}

The study was approved by the Institutional Review Board at the Kangdong Sacred Heart Hospital (KANGDONG 201705-006), Soonchunhyang University Hospital Cheonan (SCHCA 2017-08-043), Seoul St. Mary's Hospital (KC19QEDI0218), Seoul National University Bundang Hospital (B-1709/423304), Gyeongsang National University Hospital (GNUH 2017-09-008), Keimyung University Dongsan Medical Center (2017-09-017), Chungnam National University Hospital (CNUH 2017-09-003), Chonnam National University Hwasun Hospital (CNUHH-2017-135), Catholic Kwandong University International St. Mary's Hospital (IS17QIMI0053), and Severance Hospital, Yonsei Cancer Center (4-2017-0713). Written informed consent was obtained from all participants. 


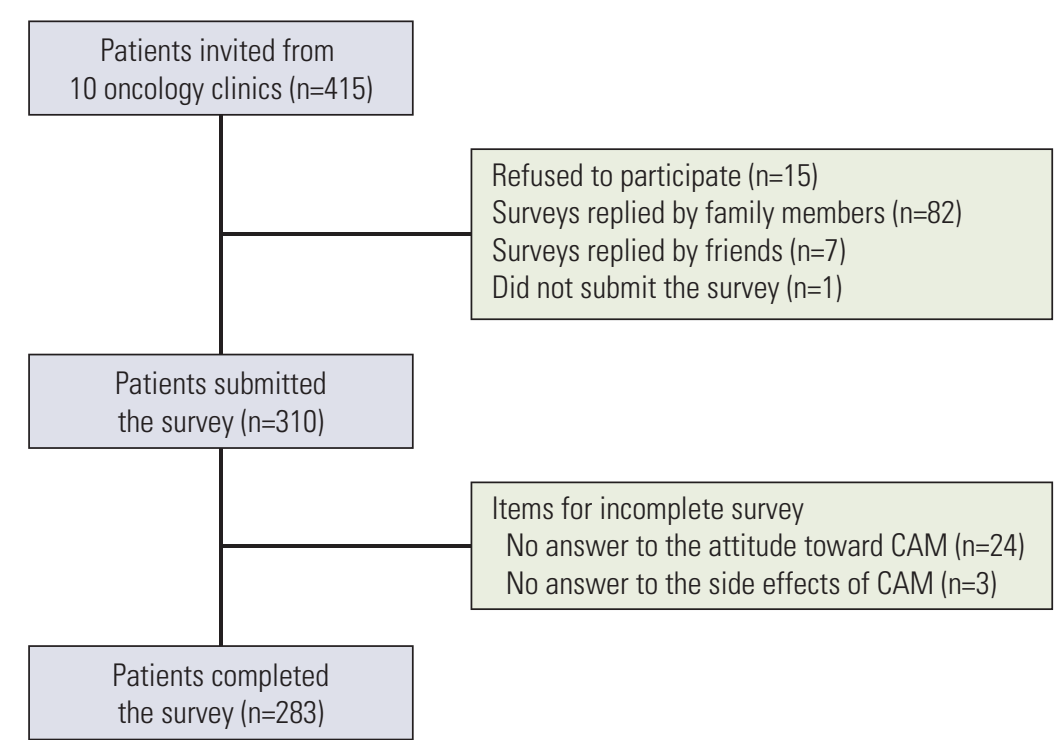

Fig. 1. Study consort diagram. CAM, complementary and alternative medicine.

Table 1. Demographics according to CAM use

\begin{tabular}{|c|c|c|c|c|}
\hline Characteristic & $\begin{array}{c}\text { Total } \\
(n=283)\end{array}$ & $\begin{array}{l}\text { Not experienced } \\
\qquad(n=177)\end{array}$ & $\begin{array}{l}\text { Experienced } \\
\qquad(n=106)\end{array}$ & p-value \\
\hline Age (yr) & $60(52-67)$ & $62(52-67)$ & $60(52-67)$ & $0.574^{\text {a) }}$ \\
\hline \multicolumn{5}{|l|}{ Sex } \\
\hline Male & $169(59.7)$ & $113(63.8)$ & $56(52.8)$ & $0.068^{\mathrm{a})}$ \\
\hline Female & $114(40.3)$ & $64(36.2)$ & $50(47.2)$ & \\
\hline \multicolumn{5}{|l|}{ Cancer type } \\
\hline Gastrointestinal tract & $109(38.5)$ & $73(41.2)$ & $36(34.0)$ & $0.845^{\mathrm{b})}$ \\
\hline Thorax & $37(13.1)$ & $22(12.4)$ & $15(14.2)$ & \\
\hline Hepatobiliary & $37(13.1)$ & $24(13.6)$ & $13(12.3)$ & \\
\hline Breast & $36(12.7)$ & $20(11.3)$ & $16(15.1)$ & \\
\hline GY/GU & $26(9.2)$ & $14(7.9)$ & $12(11.3)$ & \\
\hline Sarcoma & $12(4.2)$ & $7(4.0)$ & $5(4.7)$ & \\
\hline Head and neck & $10(3.5)$ & $7(4.0)$ & $3(2.8)$ & \\
\hline Hematology & $8(2.8)$ & $6(3.4)$ & $2(1.9)$ & \\
\hline Other & $8(2.8)$ & $4(2.3)$ & $4(3.8)$ & \\
\hline Duration of disease (mo) & $12(4-29)$ & $10(3-22)$ & $20.5(5-39)$ & $<0.001^{\text {a) }}$ \\
\hline \multicolumn{5}{|l|}{ Advanced disease } \\
\hline Yes & $86(30.4)$ & $59(33.3)$ & $27(25.5)$ & $0.379^{\text {a) }}$ \\
\hline No & $125(44.2)$ & $75(42.4)$ & $50(47.2)$ & \\
\hline Missing & $72(25.4)$ & $43(24.3)$ & $29(27.4)$ & \\
\hline \multicolumn{5}{|l|}{ Current treatment } \\
\hline Active treatment & $2(0.7)$ & $2(1.1)$ & 0 & $0.792^{b)}$ \\
\hline Palliative care & $278(98.2)$ & $173(97.7)$ & $105(99.1)$ & \\
\hline Unknown & $3(1.1)$ & $2(1.1)$ & $1(0.9)$ & \\
\hline \multicolumn{5}{|l|}{ Belief in CAM } \\
\hline Yes & $204(72.1)$ & $115(65.0)$ & $89(84.0)$ & $<0.001^{\text {a) }}$ \\
\hline No & $79(27.9)$ & $62(35.0)$ & $17(16.0)$ & \\
\hline
\end{tabular}

Values are presented as median (IQR) or number (\%). CAM, complementary and alternative medicine; GY / GU, gynecological/genitourinary tumor; IQR, interquartile range. ${ }^{\text {a) }}$ Chi-square test, ${ }^{b}$ Fisher exact test. 
A

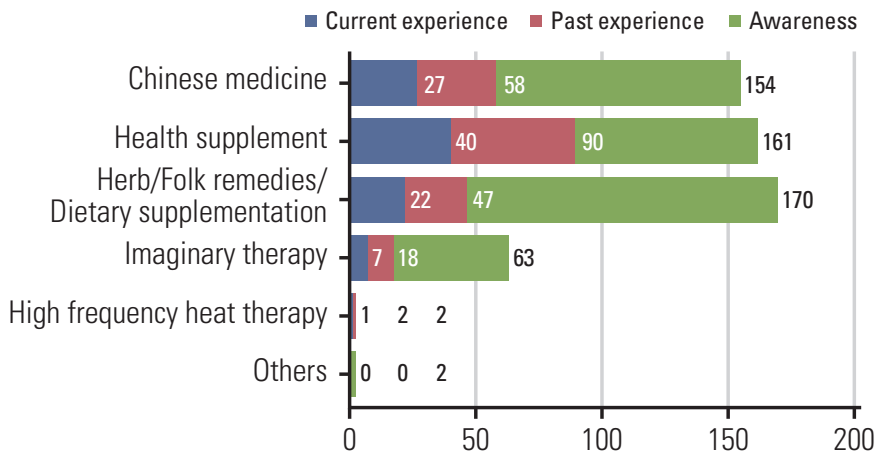

Satisfaction score with CAM

- 03-median 01-median

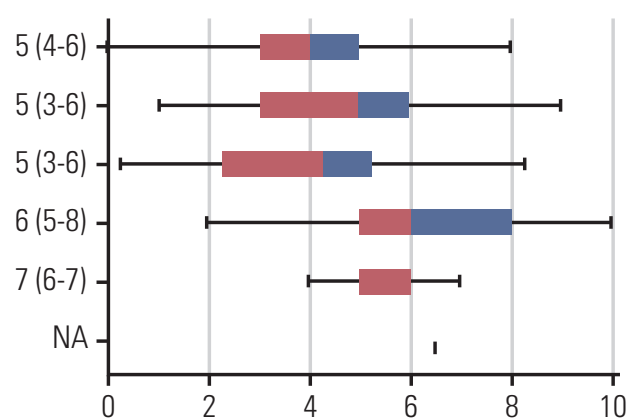

Fig. 2. Satisfaction with complementary alternative medicine according to complementary and alternative medicine (CAM) modalities in 283 patients. (A) Number of patients who are aware of the types of CAM, those who have previously used CAM, and those who are current CAM users. (B) Satisfaction score (0-10) for each CAM modality in 106 patients. The median and quartile values are displayed; Q1-Q3, 1st quartile-3rd quartile. NA, not available.

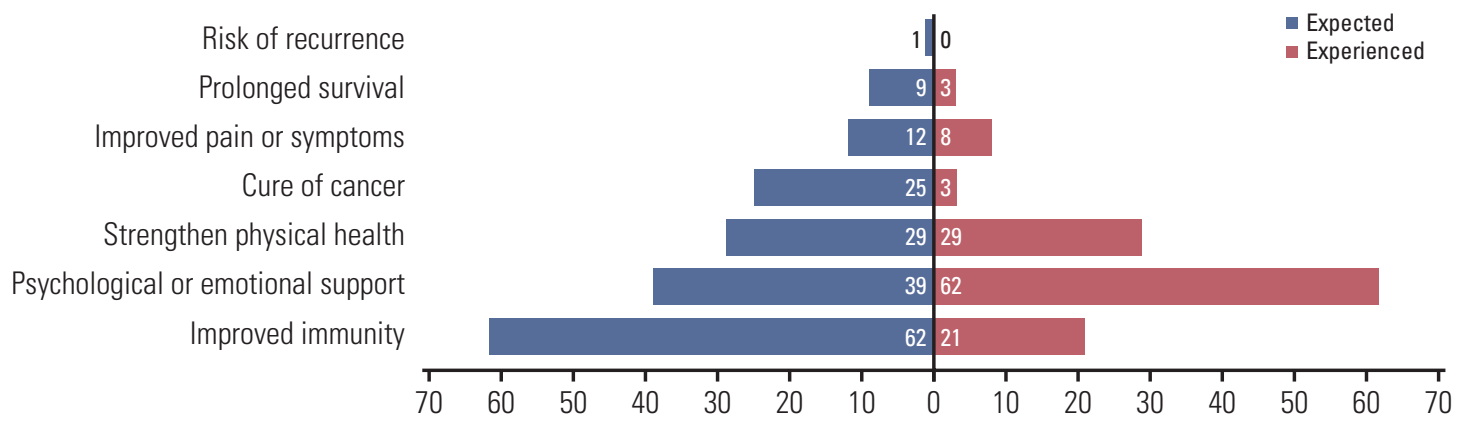

Fig. 3. Patients' answers on multiple-choice questions regarding their expectations about complementary and alternative medicine (CAM) before use (left side) and met their expectancy after using CAM (right side).

\section{Results}

\section{Participant characteristics}

Between September 21 and October 31, 2017, 415 patients and family members were invited to participate in the survey. Four hundred patients agreed to take the survey among the 10 participating oncology clinics in South Korea: the response rate was 75\% (310/415), and 283 patients completed the survey (Fig. 1).

In total, 286 of 310 patients reported their attitudes toward CAM. Among 286 patients, $51(17.8 \%)$ had strong beliefs in CAM, $156(54.5 \%)$ had weak beliefs in CAM, and $79(27.6 \%)$ had no beliefs in CAM. The analysis included 283 patients because three patients did not report the satisfaction of CAM.
The patients' demographics are summarized in Table 1. The median age was 61 years, and $60 \%$ were male. Most of the patients were actively receiving anticancer treatment at the time of the survey. Groups based on the confidence in CAM modalities were not different in terms of age $(\mathrm{p}=0.574)$, sex $(\mathrm{p}=0.068)$, cancer type $(\mathrm{p}=0.845)$, or advanced disease at the time of the survey $(\mathrm{p}=0.379)$. However, duration of disease $(\mathrm{p}<0.001)$ and belief in CAM $(\mathrm{p}<0.001)$ were different according to the CAM experience.

\section{CAM experiences among the patients}

A total of 106 patients (37\%) had experienced a median of two CAM modalities (interquartile range [IQR], 1 to 3 ), and 60 of them continued to use CAM at the time of survey, with a median of one modality (IQR, 1 to 2 ). The median duration of 
Table 2. Probability of using CAM among patients $(n=283)$

\begin{tabular}{|c|c|c|}
\hline Variable & cOR $(95 \% \mathrm{CI})$ & aOR $(95 \% \mathrm{CI})$ \\
\hline Age (yr) & $0.995(0.973-1.017)$ & $0.996(0.972-1.020)$ \\
\hline Female vs. male & $1.576(0.966-2.572)$ & $1.375(0.814-2.324)$ \\
\hline \multicolumn{3}{|l|}{ Diagnosis of cancer } \\
\hline Thorax vs. GI & $1.383(0.641-2.980)$ & - \\
\hline HB vs. GI & $1.098(0.501-2.406)$ & - \\
\hline Breast vs. GI & $1.622(0.752-3.500)$ & - \\
\hline GY / GU vs. GI & $1.738(0.729-4.141)$ & - \\
\hline Sarcoma vs. GI & $1.448(0.430-4.882)$ & - \\
\hline HN vs. GI & $0.869(0.212-3.560)$ & - \\
\hline Hematology vs. GI & $0.676(0.130-3.519)$ & - \\
\hline Others vs. GI & $2.028(0.479-8.578)$ & - \\
\hline \multicolumn{3}{|l|}{ Disease status } \\
\hline Advanced disease vs. not & $1.457(0.816-2.600)$ & - \\
\hline Unknown vs. not & $1.474(0.765-2.837)$ & - \\
\hline \multicolumn{3}{|l|}{ Anticancer treatment } \\
\hline Active treatment vs. palliative care & $>999.999(<0.001->999.999)$ & - \\
\hline Unknown vs. palliative care & $>999.999(<0.001->999.999)$ & - \\
\hline Disease duration (mo) & $1.011(1.003-1.019)$ & $1.012(1.004-1.020)$ \\
\hline Belief vs. no belief & $2.823(1.543-5.162)$ & $3.015(1.611-5.640)$ \\
\hline
\end{tabular}

CAM, complementary and alternative medicine; cOR, crude odds ratio; CI, confidence interval; aOR, adjusted odds ratio controlling for age, sex, disease duration, and belief in CAM; GI, gastrointestinal tumor; HB, hepatobiliary tumors; GY / GU, gynecological/genitourinary tumor; $\mathrm{HN}$, head and neck cancer.

Table 3. Probability of current use of CAM among patients $(n=283)$

\begin{tabular}{|c|c|c|}
\hline Variable & cOR $(95 \% \mathrm{CI})$ & aOR $(95 \% \mathrm{CI})$ \\
\hline Age (yr) & $1.007(0.981-1.034)$ & $1.010(0.982-1.039)$ \\
\hline Female vs. male & $1.394(0.785-2.476)$ & $1.360(0.742-2.493)$ \\
\hline \multicolumn{3}{|l|}{ Diagnosis of cancer } \\
\hline Thorax vs. GI & $0.811(0.300-2.194)$ & - \\
\hline HB vs. GI & $1.156(0.462-2.889)$ & - \\
\hline Breast vs. GI & $1.197(0.478-3.000)$ & - \\
\hline GY / GU vs. GI & $1.862(0.714-4.861)$ & - \\
\hline Sarcoma vs. GI & $2.095(0.576-7.620)$ & - \\
\hline HN vs. GI & $1.048(0.207-5.299)$ & - \\
\hline Hematology vs. GI & $1.397(0.263-7.417)$ & - \\
\hline Others vs. GI & $0.599(0.070-5.132)$ & - \\
\hline \multicolumn{3}{|l|}{ Disease status } \\
\hline Advanced disease vs. not & $1.304(0.647-2.629)$ & - \\
\hline Unknown vs. not & $1.578(0.730-3.412)$ & - \\
\hline \multicolumn{3}{|l|}{ Anticancer treatment } \\
\hline Active treatment vs. palliative care & $>999.999(<0.001->999.999)$ & - \\
\hline Unknown vs. palliative care & $>999.999(<0.001->999.999)$ & - \\
\hline Disease duration (mo) & $1.004(0.996-1.012)$ & $1.004(0.996-1.012)$ \\
\hline Belief vs. no belief & $3.609(1.563-8.331)$ & $3.633(1.567-8.424)$ \\
\hline
\end{tabular}

CAM, complementary and alternative medicine; COR, crude odds ratio; $\mathrm{CI}$, confidence interval; aOR, adjusted odds ratio controlling for age, sex, disease duration, and belief in CAM; GI, gastrointestinal tumor; HB, hepatobiliary tumors; GY / GU, gynecological/genitourinary tumor; HN, head and neck cancer. 
each CAM modality was 4 months (IQR, 1 to 12 ). Patients who continued to use CAM reported belief in the efficacy of CAM $(\mathrm{p}<0.001)$ and reported that they were actively receiving treatment $(p=0.040)$. A total of $39 \%$ of the patients $(41 / 106)$ reported that they started using CAM at the time of diagnosis, and $27 \%(29 / 106)$ reported that they started during chemotherapy. Herb / folk remedy / dietary supplementation was the most recognized CAM modality, followed by health supplementation, Chinese medicine, and imaginary therapy. The patients' satisfaction score with imaginary therapy was relatively higher than their satisfaction with Chinese medicine, health supplementation, or herb/folk remedy/dietary supplementation (Fig. 2). Patients' expectations before using CAM and the number of answers of patients who felt that the efficacy of CAM met their expectations are presented in Fig. 3. Enhanced immunity was the most frequently reported "expected efficacy" before using CAM, while psychological or emotional support was the most frequently reported "real effect" after using CAM.

\section{Factors related to CAM experiences and continuous use}

Among the 283 patients, 106 experienced CAM and 60 used CAM at the time of the survey. Duration of disease and belief in CAM were significantly related to the experience of CAM. The odds ratios (ORs) of those two factors were still significant after controlling for age, sex, disease duration, and belief in CAM through a multivariable logistic model (disease duration: OR, 1.012; 95\% confidence interval [CI], 1.004 to 1.020; belief in CAM: OR, 3.015; 95\% CI, 1.611 to 5.640 ) (Table 2). Patients' belief in CAM was independent of related factors with current CAM use at the time of the survey after controlling for age, sex, disease duration, and belief in CAM through a multivariable logistic model (OR, 3.633; 95\% CI, 1.567 to 8.424) (Table 3). Moreover, 26 patients of 106 CAM users replied that they did not experience any efficacy from CAM. Eight percent $(9 / 106)$ reported that they experienced side effects from CAM, and herbal medication was the most common cause of side effects. Cancer type, duration of disease, active treatment, disease duration, and discussion about CAM with physician were not related to patients' feel-

Percentage of sources of information of CAM

$\square$ Family, relatives, or friends $\square$ Media $\square$ Health care professionals $\square$ SNS $\square$ Advertisement $\square$ Patient's advocacy $\square$ Pharmacy $\square$ Other $\square$ None $\square$ Unknown
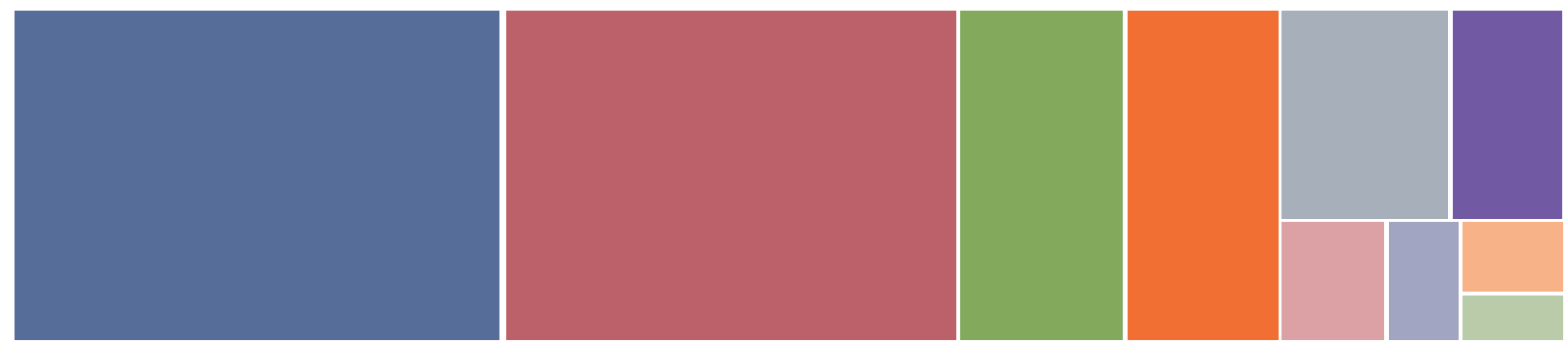

B

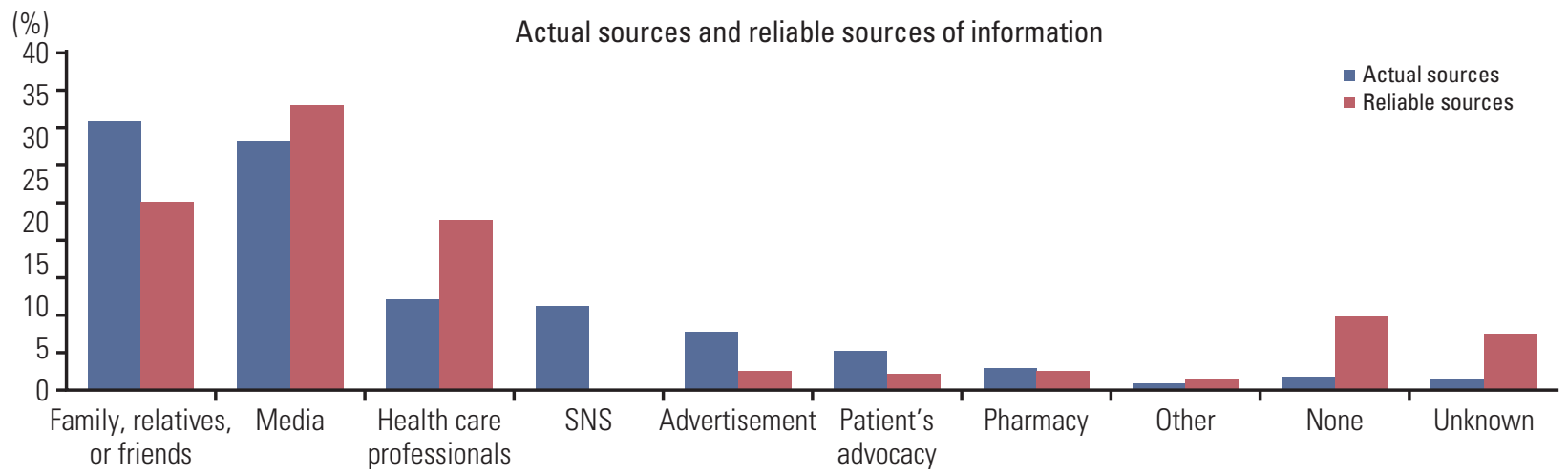

Fig. 4. Sources of information of complementary and alternative medicine (CAM): tree-map of various sources of information from all patients for multiple-choice questions on the left side (A) and the percentage of actual sources from multiple-choice questions and sources that were regarded as reliable by patients from single-choice questions on the right side (B). 
ings of effectiveness, side effects, or satisfaction in age- and sex-adjusted univariate analysis (S1-S3 Tables). We also grouped and analyzed the data by belief in CAM. Compared with those who did not believe in the efficacy of CAM, those who believed in CAM reported significantly more CAM use, the current use of a CAM modality and the experience of CAM efficacy, with ORs of 2.82 (95\% CI, 1.54 to 5.16; p < 0.001), 3.61 (95\% CI, 1.56 to 8.34; $\mathrm{p}=0.003)$, and 3.51 (95\% CI, 1.19 to $10.36 ; p=0.023)$, respectively. However, neither satisfaction with CAM nor side effects were not related to belief in CAM (S4 Table).

\section{Awareness of CAM}

Forty-three percent of patients (56/106) started CAM following recommendations from family, relatives, or friends. Twenty-four percent (25/106) received recommendations from other patients and their family members. Only $14 \%$ of patients $(15 / 106)$ started CAM by themselves. Patients gathered their CAM information from various sources, with a median number of 3 (range, 1 to 11). The most common sources of CAM information were family, relatives or friends (200/634), followed by media (186/634), healthcare professionals (68/634), social networking sites (62/634), advertisements (45/634), etc. Media (34\%), followed by family, relatives, or friends $(22 \%)$, and health care professionals $(20 \%)$ were regarded as reliable sources of information (Fig. 4). Among the patients, only $7 \%$ replied that they had sufficient knowledge of CAM, and $60 \%$ of patients reported that they had insufficient knowledge of CAM. Patients reported that they wanted more information about CAM, specifically the following: scientific evidence for efficacy $(28 \%)$; clinical trials with CAM (21\%); harmful effects, including side effects $(17 \%)$; case reports $(11 \%)$; guidelines $(10 \%)$; and an exact definition $(5 \%)$.

\section{Discussion of CAM with doctors}

Only 25\% (72/283) discussed CAM with their oncologists. In most cases (90\%), patients or family members started the discussion about CAM, and only $10 \%$ of patients reported that the discussion about CAM was initiated by healthcare professionals. These conversations included discussions of efficacy $(42 \%)$, side effects $(28 \%)$, drug interactions with conventional treatments or other CAM (26\%), the appropriate use of CAM $(2 \%)$, and restrictions during chemotherapy (1\%). Common reasons for not asking physicians in 211 patients were "not a matter to discuss with a doctor" $(49 \%, 103 / 211)$, "physicians hate to discuss CAM" $(23 \%, 48 / 211)$, and "physicians will stop my use of CAM $(18 \%, 38 / 211)$, among others.

\section{Discussion}

In our study population, positive attitudes regarding the safety and efficacy of CAM and duration of disease were associated with the experience of CAM. This result is similar to the results of a previous study that investigated the attitudes and beliefs related to CAM in cancer patients in the United States [16]. In this study by Bauml et al. [16], attitudes and beliefs related to CAM had a greater impact on the use of CAM than demographic variables such as age or sex. In this study, barriers to CAM had a negative association with the use of CAM. In contrast with the results of other studies, age and sex were not related to either the use of CAM or attitudes toward CAM in our study. The relatively lower rate of the use of CAM (37.5\% vs. 58.5\%), the heterogeneous disease group in our study population and possible cultural differences might explain these differences. The use of CAM has also been reported to have a positive association with holistic needs or concerns related to the toxicity of conventional medicine. In our study, we did not ask questions related to these concerns or barriers related to the use of CAM [17]. Additional studies are needed to further explore patient attitudes and beliefs regarding CAM use.

The prevalence of CAM use has increased in Western countries, and out-of-pocket costs for CAM modalities is enormous [18,19]. Legislation systems in European countries and the United States should make the market more transparent, which may enable greater CAM use. However, because scientific studies on the safety and effectiveness of CAM modalities are lacking, more flexible standards are applied to them than to conventional medicine [20]. Variations in regulations among European countries are considered "a substantial lack of understanding of the risks among healthcare policymakers". CAM legislation must be aligned with the regulations of conventional healthcare systems to ensure patient safety. The regulation of CAM modalities in Canada and the United States has minimal requirements for registration [21]. Some may argue that CAM has already been incorporated into conventional medication under the name of integrative medicine, and many cancer centers in the United States already provide integrative oncology in their cancer care strategies. Regardless of whether integrative oncology is promoted in cancer care, more translational and/ or clinical research is needed to understand the underlying mechanisms and clinical efficacy in terms of quality of life and overall survival, as well as to reduce the side effects of conventional medicine, the impact on adherence to conventional medicine, and drug interactions between integrative medicine and conventional oncology drugs. Until now, Asian countries have not reported enough data to provide sufficient knowledge of CAM to professionals and lay per- 
sons compared to the United States or European countries. The possibility of exposing cancer patients to unexpected harm due to CAM use in Korea is what motivated us to take the first step to fill this knowledge gap by conducting this survey.

In addition to the paucity of scientific studies on CAM, patients' attitudes about disclosing their use of CAM to their primary care physicians are concerning. In our study, only $25 \%$ (72/283) discussed using CAM with their physicians, and most of these discussions were initiated by patients or family members, not by physicians. Other studies have reported that less than $50 \%$ of patients disclose their use of CAM to their healthcare providers, and they do not disclose all types of CAM modalities [22]. Disclosure was associated with patient-related factors, including sex, ethnicity or education level, as well as their healthcare provider's perspective on CAM [23]. Non-Hispanic ethnicity, female sex, and a relatively high level of education were related to their disclosure of their use of CAM [24]. Patients tended to disclose their CAM use when the provider placed more value on CAM modalities [23]. Even though patients should be able to receive information on CAM from the healthcare professionals at the time when they consider using CAM, they do not disclose their desire to use CAM for the following reasons: (1) fear of being abandoned by their cancer doctors because they wish to use CAM modalities, (2) physician's lack of knowledge of CAM, or (3) fear of upsetting their physician [25]. The reasons for not having a discussion about CAM in our study were as follows: physicians hate to discuss CAM, physicians will stop my use of CAM, physicians have no knowledge of CAM, and it is not a matter for discussion with physicians. These reasons for not having a discussion with their physicians are similar to those reported in other studies. Patients do not disclose their use of CAM not only because of their physician's lack of knowledge of CAM but also because they do not want to discuss their dissatisfaction with the conventional medical system [26]. To facilitate the discussion of CAM between patients and physicians, CAM education programs should be developed-not only for patients but also for physicians [27]. Developing an education program for CAM could help improve patient-doctor communication related to CAM and protect patients from unexpected, harmful effects of CAM.

Patients' sources of information constitute another problem that remains to be solved. Physicians as well as patients need more information about CAM. In our study, 132 patients wanted information related to the scientific evidence of CAM efficacy, and 96 wanted to know about clinical trials on CAM. However, their sources of information were family, relatives, and friends $(32 \%)$ and media and social networking sites $(40 \%)$, with their most trusted source of information being media (34\%). Another study reported that lay referral and media were also used by cancer patients to gather information about CAM [28]. Family endorsement was also reported to affect patients' expectations of CAM in terms of clinical efficacy [29]. It is not easy to find scientific evidence on CAM in Korean on websites; therefore, we need to focus on ensuring that these data are available to Korean patients.

The design of this cross-sectional study has some limitations in confirming the relationships between patients' expectations of CAM efficacy and their feelings of effectiveness and satisfaction. Young age, chronic illness, including cancer, and level of education were reported to have impacts on the use of CAM or CAM experiences. Cancer type has also been associated with CAM-related behaviors. To validate our study, prospective observational studies are needed that control for confounding factors.

\section{Electronic Supplementary Material}

Supplementary materials are available at Cancer Research and Treatment website (https://www.e-crt.org).

\section{Conflicts of Interest}

Conflict of interest relevant to this article was not reported.

\section{Acknowledgments}

This is a Planning Task of the General Affairs Committee of the Korean Cancer Association. The authors would like to express our appreciation to the secretariat members of the Korean Cancer Association, as well as to the patients and family members who participated in this study.

\section{Author Details}

${ }^{1}$ Division of Hemato-Oncology, Department of Internal Medicine, Kangdong Sacred Heart Hospital, Hallym University College of Medicine, Seoul, '2Department of Internal Medicine, Soonchunhyang University Cheonan Hospital, Cheonan, ${ }^{3}$ Division of Medical Oncology, Department of Internal Medicine, Cancer Research Institute, Seoul St. Mary's Hospital, College of Medicine, The Catholic University of Korea, Seoul, ${ }^{4}$ Division of Hematology and Medical Oncology, Seoul National University Bundang Hospital, Seoul National University College of Medicine, Seongnam, ${ }^{5}$ Division of Hematology-Oncology, Department of Internal Medicine, Institute of Health Sciences, Gyeongsang National University School of Medicine, Jinju, ${ }^{6}$ Division of Hematology-Oncology, Department of Internal Medicine, Keimyung University Dongsan Medical Center, Keimyung University School of Medicine, Daegu, ${ }^{7}$ Department of Internal Medicine, Chungnam National University School of Medicine, Daejeon, ${ }^{8}$ Department of Internal Medicine, Chonnam National University Hwasun Hospital, Hwasun, ${ }^{9}$ Division of Medical 
Oncology, Department of Internal Medicine, Catholic Kwandong University International St. Mary's Hospital, Incheon, ${ }^{10}$ Department of Radiation Oncology, Seoul National University College of Medicine, Seoul, ${ }^{11}$ Division of Colorectal Surgery, Department of Surgery, Korea University College of Medicine, Seoul, ${ }^{12}$ Division of
Oncology / Hematology, Department of Internal Medicine, Korea University College of Medicine, Seoul, ${ }^{13}$ Division of Medical Oncology, Department of Internal Medicine, Yonsei Cancer Center, Yonsei University College of Medicine, Seoul, Korea

\section{References}

1. Torre LA, Bray F, Siegel RL, Ferlay J, Lortet-Tieulent J, Jemal A. Global cancer statistics, 2012. CA Cancer J Clin. 2015;65:87108.

2. Jung KW, Won YJ, Kong HJ, Lee ES; Community of Population-Based Regional Cancer Registies. Cancer statistics in Korea: incidence, mortality, survival, and prevalence in 2015. Cancer Res Treat. 2018;50:303-16.

3. Rashrash M, Schommer JC, Brown LM. Prevalence and predictors of herbal medicine use among adults in the United States. J Patient Exp. 2017;4:108-13.

4. Buckner CA, Lafrenie RM, Denommee JA, Caswell JM, Want DA. Complementary and alternative medicine use in patients before and after a cancer diagnosis. Curr Oncol. 2018;25:e27581.

5. Berretta M, Della Pepa C, Tralongo P, Fulvi A, Martellotta F, Lleshi A, et al. Use of complementary and alternative medicine (CAM) in cancer patients: an Italian multicenter survey. Oncotarget. 2017;8:24401-14.

6. Choi JY, Chang YJ, Hong YS, Heo DS, Kim S, Lee JL, et al. Complementary and alternative medicine use among cancer patients at the end of life: Korean national study. Asian Pac J Cancer Prev. 2012;13:1419-24.

7. Scott JA, Kearney N, Hummerston S, Molassiotis A. Use of complementary and alternative medicine in patients with cancer: a UK survey. Eur J Oncol Nurs. 2005;9:131-7.

8. Hlubocky FJ, Ratain MJ, Wen M, Daugherty CK. Complementary and alternative medicine among advanced cancer patients enrolled on phase I trials: a study of prognosis, quality of life, and preferences for decision making. J Clin Oncol. 2007;25:54854.

9. John GM, Hershman DL, Falci L, Shi Z, Tsai WY, Greenlee H. Complementary and alternative medicine use among US cancer survivors. J Cancer Surviv. 2016;10:850-64.

10. Tascilar M, de Jong FA, Verweij J, Mathijssen RH. Complementary and alternative medicine during cancer treatment: beyond innocence. Oncologist. 2006;11:732-41.

11. World Health Organization. Traditional, complementary and integrative medicine [Internet]. Geneva: World Health Organization; 2019 [cited 2019 Feb 5]. Available from: https:// www. who.int/traditional-complementary-integrative-medicine/ about/en/.

12. National Center for Complementary and Integrative Health. The use of complementary and alternative medicine in the United States [Internet]. Bethesda, MD: National Center for
Complementary and Integrative Health; c2008 [cited 2018 Dec 16]. Available from: https: / / nccih.nih.gov/ research/statistics/2007/ camsurvey_fs1.htm.

13. Meijerman I, Beijnen JH, Schellens JH. Herb-drug interactions in oncology: focus on mechanisms of induction. Oncologist. 2006;11:742-52.

14. Mohd Mujar NM, Dahlui M, Emran NA, Abdul Hadi I, Wai YY, Arulanantham S, et al. Complementary and alternative medicine (CAM) use and delays in presentation and diagnosis of breast cancer patients in public hospitals in Malaysia. PLoS One. 2017;12:e0176394.

15. Nahin RL, Barnes PM, Stussman BJ. Expenditures on complementary health approaches: United States, 2012. Natl Health Stat Report. 2016;(95):1-11.

16. Bauml JM, Chokshi S, Schapira MM, Im EO, Li SQ, Langer CJ, et al. Do attitudes and beliefs regarding complementary and alternative medicine impact its use among patients with cancer? A cross-sectional survey. Cancer. 2015;121:2431-8.

17. Barrett B, Marchand L, Scheder J, Plane MB, Maberry R, Appelbaum D, et al. Themes of holism, empowerment, access, and legitimacy define complementary, alternative, and integrative medicine in relation to conventional biomedicine. J Altern Complement Med. 2003;9:937-47.

18. Institute of Medicine, Committee on the Use of Complementary and Alternative Medicine by the American Public. Complementary and alternative medicine in the United States. Washington, DC: National Academies Press; 2005. p. 34-64.

19. Eardley S, Bishop FL, Prescott P, Cardini F, Brinkhaus B, Santos-Rey K, et al. CAM use in Europe: the patients' perspective. Part I: a systematic literature review of CAM prevalence in the EU. Southampton: University of Southampton; 2012.

20. Alostad AH, Steinke DT, Schafheutle EI. International comparison of five herbal medicine registration systems to inform regulation development: United Kingdom, Germany, United States of America, United Arab Emirates and Kingdom of Bahrain. Pharmaceut Med. 2018;32:39-49.

21. Job KM, Kiang TK, Constance JE, Sherwin CM, Enioutina EY. Herbal medicines: challenges in the modern world. Part 4. Canada and United States. Expert Rev Clin Pharmacol. 2016;9: 1597-609.

22. Mehta DH, Gardiner PM, Phillips RS, McCarthy EP. Herbal and dietary supplement disclosure to health care providers by individuals with chronic conditions. J Altern Complement Med. 2008;14:1263-9. 
23. Tarn DM, Karlamangla A, Coulter ID, Paterniti DA, Knox L, Khang PS, et al. A cross-sectional study of provider and patient characteristics associated with outpatient disclosures of dietary supplement use. Patient Educ Couns. 2015;98:830-6.

24. Kennedy J, Wang CC, Wu CH. Patient disclosure about herb and supplement use among adults in the US. Evid Based Complement Alternat Med. 2008;5:451-6.

25. Farooqui M, Hassali MA, Abdul Shatar AK, Shafie AA, Farooqui MA, Saleem F, et al. Complementary and alternative medicines (CAM) disclosure to the health care providers: a qualitative insight from Malaysian cancer patients. Complement Ther Clin Pract. 2012;18:252-6.

26. Ernst $\mathrm{E}$. The role of complementary and alternative medicine. BMJ. 2000;321:1133-5.
27. Corbin Winslow L, Shapiro H. Physicians want education about complementary and alternative medicine to enhance communication with their patients. Arch Intern Med. 2002; 162:1176-81.

28. Evans M, Shaw A, Thompson EA, Falk S, Turton P, Thompson $\mathrm{T}$, et al. Decisions to use complementary and alternative medicine (CAM) by male cancer patients: information-seeking roles and types of evidence used. BMC Complement Altern Med. 2007;7:25.

29. Latte-Naor S, Sidlow R, Sun L, Li QS, Mao JJ. Influence of family on expected benefits of complementary and alternative medicine $(\mathrm{CAM})$ in cancer patients. Support Care Cancer. 2018;26:2063-9. 